\title{
Article \\ The Direct Cause of Amplified Wettability: Roughness or Surface Chemistry?
}

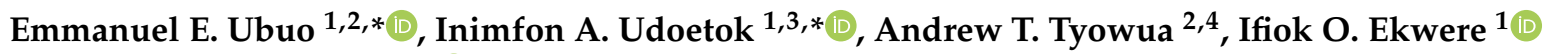 \\ and Hamza S. Al-Shehri ${ }^{2,5}$ \\ 1 Department of Chemistry, Akwa Ibom State University, Mkpat Enin, Akwa Ibom State, Nigeria; \\ ifiokekwere@aksu.edu.ng \\ 2 Department of Chemistry and Biochemistry, University of Hull, Hull HU6 7RX, UK; \\ a.tyowua@gmail.com (A.T.T.); h.s.alshehri@outlook.com (H.S.A.-S.) \\ 3 Prairie Lithium, Emerald Park, SK S4L 1B7, Canada \\ 4 Applied Colloid Science and Cosmeceutical Group, Department of Chemistry, Benue State University, \\ Makurdi, Benue State, Nigeria \\ 5 Chemistry Division, King Khaled Military Academy, SANG, Riyadh 11564, Saudi Arabia \\ * Correspondence: eubuo@yahoo.co.uk (E.E.U.); inimfon.udoetok@usask.ca (I.A.U.)
}

check for updates

Citation: Ubuo, E.E.; Udoetok, I.A.; Tyowua, A.T.; Ekwere, I.O.; Al-Shehri, H.S. The Direct Cause of Amplified Wettability: Roughness or Surface Chemistry? J. Compos. Sci. 2021, 5, 213. https://doi.org/10.3390/ jcs5080213

\section{Academic Editors:}

Francesco Tornabene and

Thanasis Triantafillou

Received: 6 July 2021

Accepted: 4 August 2021

Published: 12 August 2021

Publisher's Note: MDPI stays neutral with regard to jurisdictional claims in published maps and institutional affiliations.

Copyright: (c) 2021 by the authors. Licensee MDPI, Basel, Switzerland. This article is an open access article distributed under the terms and conditions of the Creative Commons Attribution (CC BY) license (https:/ / creativecommons.org/licenses/by/ $4.0 /)$.

\begin{abstract}
Higher contact angles or amplified wettability observed on surfaces of rough solid materials are typically expressed as a function of a physical dimension (roughness factor). Herein, we present a simple experimental approach that demonstrates that roughness may only magnify the inherent surface chemistry that seems to have direct influence on surface wettability. We investigate gradual change in surface chemistry (hydrophobisation) of rough and smooth glass surfaces, from a very low concentration $\left(10^{-7} \mathrm{M}\right)$ of dichlorodimethylsilane, DCDMS through various intermediate hydrophilic/hydrophobic states to when the surfaces are maximally hydrophobised with DCDMS at $0.1 \mathrm{M}$. The wettability of the modified glasses was studied by water contact angle measurements using drop shape analysis system (DSA). The data obtained indicate a deviation from Wenzel model, with the functionalized rough glass surfaces showing higher reactivity towards DCDMS when compared to the smooth glass surfaces, indicating that the two surfaces are not chemically identical. Our study reveals that just like transforming a solid material to powder, a well-divided glass (rough) surface may not only exhibit a greater surface area than the smooth counterpart as rightly predicted by the Wenzel model, but seems to be bloated with functional groups $\left(-\mathrm{OH}\right.$ or $\left.-\mathrm{CH}_{3}\right)$ that can amplify surface interaction when such functional species dominate the solid surface.
\end{abstract}

Keywords: amplified wettability; functional groups; hydrophobisation; roughness; surface chemistry

\section{Introduction}

The behaviour of solids at the solid-water interface has been a subject of immense research interest and is widely reported [1-3]. The reports reveal that surface texture and surface energy play significant roles in determining the extent of surface wettability [4-6]. However, surface energy is directly related to surface chemistry and depends on the type of chemical bonds on the material's surface [7]. Though direct measurement of the surface energy of solid materials is difficult, it may be indirectly determined through measurement of the contact angle of liquid droplets on the solid materials [8,9]. Contact angles of liquid droplets on solid materials have been employed in the prediction of wettability and surface energies of different materials. In particular, materials with high surface energy are hydrophilic and water droplets over their surfaces exhibit contact angles below $90^{\circ}$. On the other hand, materials with low surface energy tend to be hydrophobic, where the contact angles of water droplets on their surfaces are greater than $90^{\circ}$. Apart from the materials composition, nature of the liquid, $\mathrm{pH}$ of the liquid and the temperature of the surface and/or the liquid can also influence the contact angle [10-12]. 
Following several investigations on wetting phenomena, the Young's model, denoted by the equation in Figure 1a [13] appears to be the fundamental model that provides good description of the wettability of solids. The model relies on the solid-air interfacial tension $\left(\gamma_{S A}\right)$ and its relationship with the solid-liquid interfacial tension $\left(\gamma_{S L}\right)$ and surface tension or liquid -air interfacial tension $\left(\gamma_{L A}\right)$. The model further assumes that the parameters all act at the interface of a liquid droplet on an ideally smooth, nonreactive, non-deformed solid surface and air. Though such surfaces are difficult to attain, relatively smooth surfaces are commonly used in wetting studies. Experimental studies on smooth surfaces reveal that the contact angle of water droplets on such surfaces may be up to $120^{\circ}$, where higher contact angles are only possible on real surfaces with different levels of heterogeneity [14]. Notably, the leaves of some plants such as lotus and desert beetle have been shown to exhibit rough or micro-textured surfaces of various designs [15]. The unique features of these organisms allow them to exhibit adaptable and extreme wetting behaviours.
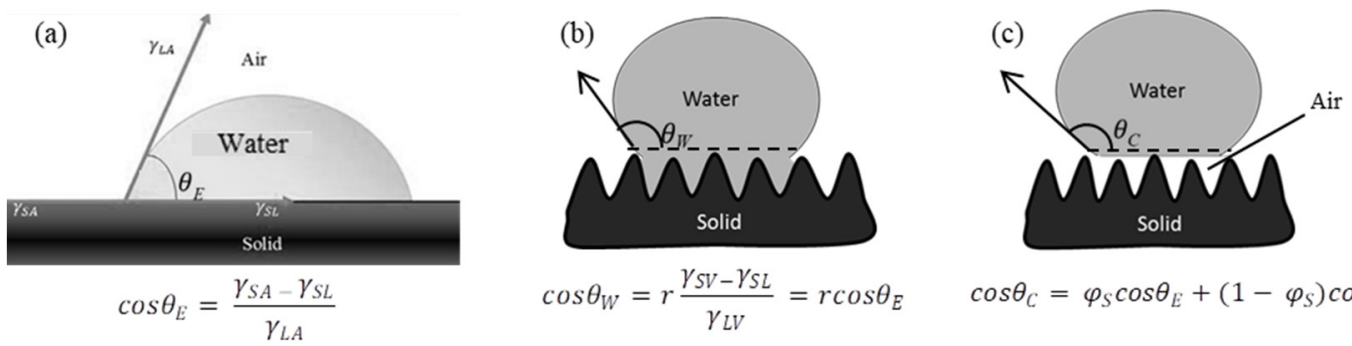

Figure 1. Illustration of the Young (a) Wenzel (b) Cassie-Baxter (c) wetting models. The arrows represent forces, solid-air interfacial tension $\left(\gamma_{S A}\right)$, solid-liquid interfacial tension $\left(\gamma_{S L}\right)$ and surface tension of liquid $\left(\gamma_{L A}\right)$ acting on the three-phase contact line of a liquid drop on a smooth solid surface in air. $\theta_{E}$ is the Young equilibrium contact angle, $\varphi_{S}$ and $\left(1-\varphi_{S}\right)$ are the fractions of the solid surface in contact with the liquid and the fraction of air in contact with the liquid on Cassie-Baxter surface, respectively. $\theta_{a}$ is the contact angle of the air portion and $\theta_{W}$ represents the Wenzel apparent contact angle and $r$ is the roughness factor (the ratio of the true surface area of the solid to its horizontal projection).

Young's assumption did not consider surface roughness which informs the inability of his model equation to provide a good description of wetting behaviours on rough surfaces. On the other hand, early studies on the wettability of rough solid surfaces were reported by Wenzel [16] and Cassie-Baxter [17]. Nevertheless, the model equations propounded by Wenzel and Cassie-Baxter were achieved by modification of the Young's equation to accommodate roughness or heterogeneity on real surfaces. Wenzel model, on the other hand, considers homogeneous wetting in which the liquid wets a rough surface and maintains intimate contact with the top and the hollow portions of the rough solid material [18] (see Figure 1b).

In Wenzel equation, the roughness factor $r$, which is the ratio of the real surface area of the solid to the projected surface area, is greater than 1 (i.e., $r>1$ ). Thus, the precise interpretation of Wenzel model reveals that for a hydrophilic surface of the same material where $\theta$ is less than $90^{\circ}$, a rough surface exhibits contact angle $\left(\theta_{W}\right)$ smaller than the contact angle of a flat surface $\left(\theta_{E}\right)$. On the other hand, for a hydrophobic flat surface with $\theta$ greater than $90^{\circ}, \theta_{W}$ becomes greater than $\theta_{E}$ [19]. The $r$ in Wenzel equation represents only the physical dimension of the surface, otherwise a change in surface energy arising from the increased surface area would accompany the $r$ [20].

In Cassie-Baxter theory, liquid droplets sit on heterogeneous interfaces and bridges across the top structural features of the rough surface such that the droplets rest on top while the grooves are occupied by other material(s) like air. In an air-trapped Cassie-Baxter solid surface, water sits on both the solid and air to create liquid-air and solid-liquid composite interfaces (see Figure 1c). However, this paper is more interested in Wenzel surface.

Although Wenzel mode of wetting provides useful insight into wetting studies, the validity of the model has been disputed [20-26]. As earlier described by the Wenzel model, enhanced wettability observed on rough solid surfaces is based on a geometry (roughness 
factor) which is a physical dimension. Contrary to this basic idea, Quere [20] predicted in his analysis that roughness should increase both the geometry and the solid energies. However, based on the literature review, there is no reported experimental finding that has clearly linked the amplified wettability of the rough surfaces to their surface chemistry (or energy). In this study, to further throw more light on the wettability of rough surfaces, we simultaneously study the hydrophobisation and wettability of smooth and rough surfaces of a particular glass material using different concentrations of dichlorodimethylsilane (DCDMS) and contact angle measurements, respectively. In particular, we investigate gradual changes in the chemistry of the glass surfaces from their natural hydrophilic states through various intermediate hydrophilic/hydrophobic states to when the surfaces are maximally hydrophobised. Evaluation of the surface modifications in terms of wettability allowed us to carefully elucidate the effect of roughness on surface chemistry and the possible cause of the amplified wettability on rough surfaces. The work does not aim to challenge the existing wetting models; however, it aims at revealing new ways of evaluating rough surface wettability. The study will contribute to a greater understanding of the wettability of rough surfaces in the following ways:

(i) highlighting the effects of surface chemistry of the materials in elucidation of the differences between the wettability of smooth solid surface and fractal solid surfaces;

(ii) evaluating the effectiveness of surface roughness in enhancing solid surface dimension as well as inherent surface chemistry.

\section{Materials and Methods}

\subsection{Materials}

Deionised water with $\mathrm{pH} 6.7$ was obtained from Milli-Q reverse osmosis unit (Millipore). The surface tension of the water $\left(25^{\circ} \mathrm{C}\right)$ was $72.5 \pm 0.3 \mathrm{mN} / \mathrm{m}$. The surface tension was measured using a pendant drop method (Kruss Drop shape analyser DSA 10, Hamburg, Germany). Measurements were performed by producing a pendant drop (top-to-bottom) of water from a Hamilton syringe (needle diameter $1.649 \mathrm{~mm}$ ), recording the drop shape with a CCD camera and then fitting the Young-Laplace equation to the drop image. The water was used for cleaning and as a probe liquid in wetting tests. Absolute ethanol (analytical grade), chloroform and potassium hydroxide (analytical grade) were obtained from Fisher Scientific, Loughborough, UK. Ethanol was used for the termination of the hydrophobisation reactions and surface cleaning. Alcoholic potassium hydroxide (prepared by dissolving $200 \mathrm{~g}$ of $\mathrm{KOH}$ in $3 \mathrm{dm}^{3}$ of ethanol) was used for the cleaning of the glass slides, glassware and Teflon tubes (hydrophobisation vessels). DCDMS (99.5\%) was purchased from Sigma-Aldrich, Gillingham, UK and used for the hydrophobisation of glass slides. Anhydrous toluene (99.85\%, extra dry over molecular sieve, Acros Organics) was purchased from Fisher Scientific, Gillingham, UK. It was used for preparing different concentrations of DCDMS. Microscope glass slides were premium pathology grades and were purchased as smooth hydrophilic slides from Heathrow Scientific, Nottingham, United Kingdom. Apart from smooth glasses, the surfaces of some of these glasses were roughened prior to use.

\subsection{Preparation of Glass Slides}

Roughness was created on the glass surfaces by sandblasting one side of the glasses with F320 alumina sandblasting grit (average grain size: $29 \pm 2 \mu \mathrm{m}$ ) using Guyson cabinet sandblasting machine. The glasses were cut to $12.5 \times 7.5 \mathrm{~mm}^{2}$ and cleaned with alcoholic potassium hydroxide for $30 \mathrm{~min}$ in an ultrasonic bath. The cleaning was repeated twice using copious amount of milli-Q water for $10 \mathrm{~min}$ and then dried at ambient conditions.

\subsection{Hydrophobisation Process}

The Microscope glass slides were hydrophobised using six different concentrations of DCDMS (ranging from $10^{-7} \mathrm{M}$ to $0.1 \mathrm{M}$ ) in anhydrous toluene. To avoid interference during the hydrophobisation reaction, the glass volumetric flask used for the preparation 
of the silane was pre-treated overnight with $0.5 \mathrm{~mL}$ DCDMS and subsequently washed with chloroform and ethanol to remove excess DCDMS. The glass slides were introduced into each of the six reaction vessels $\left(40 \mathrm{~cm}^{3}\right.$ Teflon centrifuge tubes, Oak Ridge, TN, USA) containing various concentrations of DCDMS. The vessels were placed in an air-tight box, fitted with gas inlet and outlet. The box was placed on multipoint stirrers (Thermo Electron, Cheshire, United Kingdom) and saturated with dry nitrogen gas. The set-up was monitored for one hour with intermittent flushing using nitrogen gas (15 min interval) to ensure a negligible increase in humidity. The chemical reactions were terminated by adding $0.5 \mathrm{~mL}$ of ethanol to each vessel and then washed with chloroform and ethanol for $10 \mathrm{~min}$ before storage in desiccators.

\subsection{Surface Morphology}

The morphology the glasses were examined using an Olympus BX 51 optical microscope (Olympus, Tokyo, Japan) with phase contrast objectives and the images were captured with a DP 70 Olympus digital camera (Japan) using Image Pro Plus Software (Rockville, MD, USA).

\subsection{Contact Angle Measurement}

Contact angles of sessile water droplets on the prepared surfaces were determined using a drop shape analysis instrument (Kruss DSA 10, Hamburg, Germany). Water drops were dispensed and withdrawn from the surfaces of the sample on the sample stage of the instrument using a syringe pump (NE1000, New Era Pump Systems Inc., New York, NY, USA) fitted with Teflon tubing and a needle. A small sessile drop of about $4 \mu \mathrm{L}$ was initially dispensed on the substrate and the droplet inflated by gradual pumping more liquid at the rate of $0.2 \mu \mathrm{L} / \mathrm{s}$. Increasing the drop volume resulted in contact line advancing outward and consecutive contact angles of the drop during the advancement were recorded until a maximum of $15 \mu \mathrm{L}$ drop was dispensed. After a stable drop was formed, the syringe pump was reversed and water withdrawn from the inflated drop at the same rate to obtained series of receding contact angles. Each reported contact angle measurement was an average reading from six droplets on three replicate samples.

\section{Results}

\subsection{Surface Morphology of Glass Surfaces}

Images of the smooth and rough glasses are shown in Figure 2. As can be estimated from the scale bars, the glass was mildly roughened to ensure Wenzel regime of wetting at hydrophilic and hydrophobic states. Very rough hydrophobic solids can change to Cassie-Baxter surface (i.e., when $r \gg 1$ ) [20].
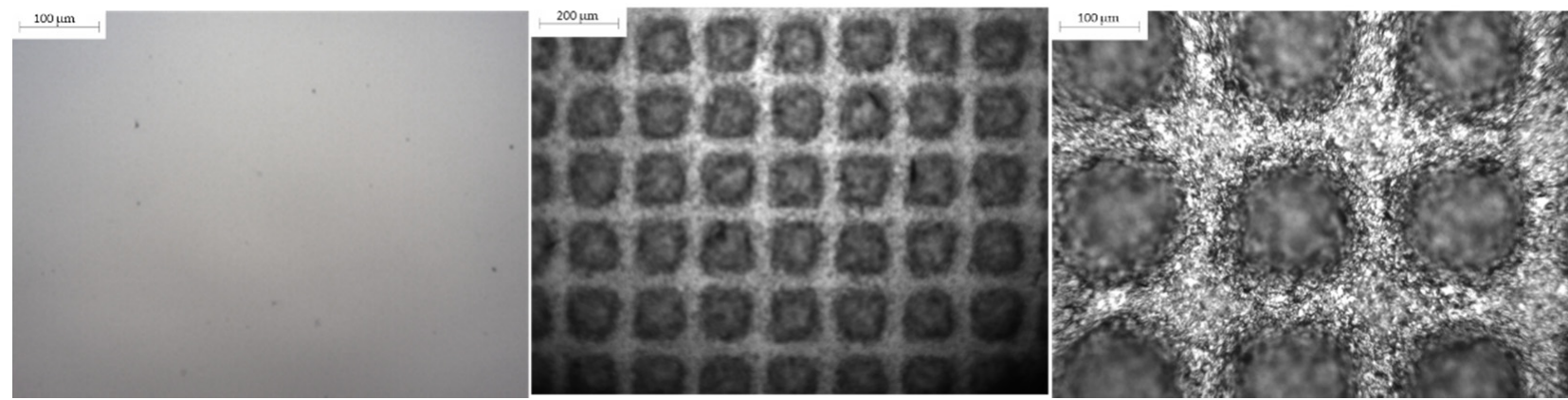

Figure 2. Microscope images of the smooth glass (left) and rough glass at different magnifications (middle and right), respectively. Scale bars (from left to right) represent 100, 200 and $100 \mu \mathrm{m}$.

\subsection{Hydrophobisation Reactions of Glass Surfaces}

Silanes are known to react with the silanol groups $(\equiv \mathrm{SiOH})$ from glass and other hydroxylated surfaces to form Si-O-Si bonds [27,28]. The reaction is possible because, in 
addition to organic active groups, silanes also contain inorganic functional groups (e.g., $-\mathrm{Cl})$ that can allow bonding with the hydroxyl groups $(-\mathrm{OH})$ on glass surface. DCDMS can self-assemble into very stable siloxane coatings and is recommended for the modification of hydroxylated oxide surfaces like silica or glass [28,29]. Interaction of the silane or DCDMS with the glass surface allows hydroxyl groups on the surface of the hydrophilic glass to be replaced with non-polar alkyl groups of the silane and, as a result, creating a hydrophobic surface (cf. Scheme 1) [30-32]. The hydrophobisation in this case modifies the surface chemistry of the glass and therefore alters its surface energy. In line with the procedure in this work, the degree of surface modification can be controlled by varying the concentration of silane [32-34].

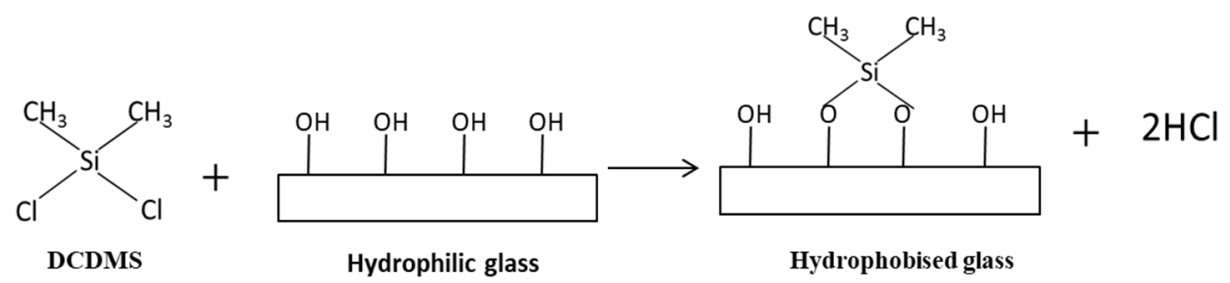

Scheme 1. The schematic illustration of hydrophobisation reactions of glass surface using DCDMS.

\subsection{Wettability of the Smooth and Rough Glass Surfaces}

Modification of glass surfaces was characterised by water contact angle measurements. Results of the contact angles of water droplets on surfaces produced at various levels of hydrophobisation are presented graphically in Figure 3. Figure 3 clearly shows that hydrophobisation of the smooth and rough glass surfaces increase with increasing concentration of DCDMS as expected. However, the rough glass exhibits higher degree of hydrophobisation in all the media studied. In addition, significantly, the wettability trend on the hydrophobised rough surfaces does not strictly follow Wenzel model. For instance, the untreated rough glass slide (at 0 M DCDMS) is more hydrophilic than the untreated smooth ones, showing contact angle of about $22^{\circ}$ for the smooth and $7^{\circ}$ for the rough glass. These initial results seem to be in agreement with the Wenzel model but the contact angle results obtained from the mildly hydrophobised rough glasses (at $10^{-7}$ to $10^{-4} \mathrm{M}$ DCDMS) do not comply with Wenzel model. The contact angles of the smooth surfaces against the rough glass are $30^{\circ}: 32^{\circ}, 39^{\circ}: 50^{\circ}, 61^{\circ}: 71^{\circ}$ and $85^{\circ}: 99^{\circ}$. It should be noted that the smooth glass surfaces are all hydrophilic at these levels of modifications $\left(\theta<90^{\circ}\right)$. According to the Wenzel model, roughness should have amplified the hydrophilicity, perhaps like the inserted imaginary (dashed) line in Figure 3. As the name implies, the imaginary line is just inserted to illustrate the Wenzel mode of wetting which allows the hydrophilic rough surface to become more hydrophilic at contact angles below $90^{\circ}$, or more hydrophobic for contact angle above $90^{\circ}$. At higher degree of surface modification $\left(10^{-3} \mathrm{M}\right.$ to $0.1 \mathrm{M}$ DCDMS), the rough surfaces maintain a steady amplification of hydrophobicity over the smooth glass and conforms to the Wenzel model. A careful analysis of the plots reveals that the wettability of the untreated and highly hydrophilic rough glasses will lead to Wenzel model. However, the choice of the gradual hydrophobisation process from very low concentrations allowed us to carefully trace and uncover the hidden wetting properties of the rough surface. This further confirms the sensitivity of structured surfaces and how they can respond to little changes that may not be observed on smooth surfaces [35].

What could be the cause of higher reactivity or hydrophilicity observed on the surface of untreated rough glass slide? According to the collision theory, when solid material is transformed to a powder or a finely divided solid (roughened surface), its reactivity is bound to increase due to an increases in the total surface area of the solid which in turn increases the number of active sites leading to greater chances of collision and reactivity [36-39]. Recently, rough materials (ultrafine jagged platinum nanowires) have been proven to provide additional sites for ultrahigh energy-generating (oxygen reduction) reactions [40] and hydrogen evolution reactions [36]. Thus, we assume that besides the 
increased surface area created by the roughening of the glass slides, an increase in the number of active surface functional groups (or bonding sites) on the rough surface should be considered (cf. Figure 4).

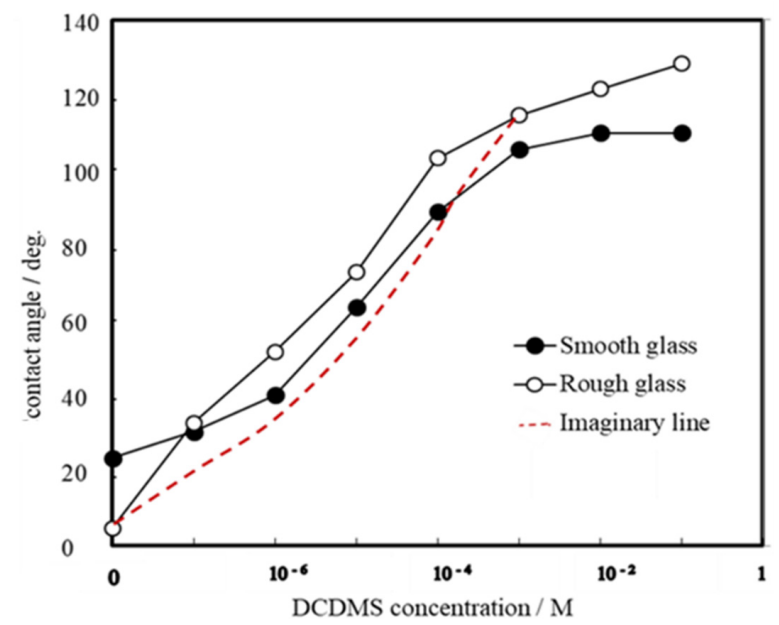

Figure 3. Dynamic contact angle of water droplets on smooth (filled symbol) and rough (opened symbol) surfaces glass slides before hydrophobisation with DCDMS (0 M) and when gradually hydrophobised through serial concentrations of DCDMS. Imaginary (dashed) line shown in the plot represents the hypothetical curve for Wenzel rough surface.

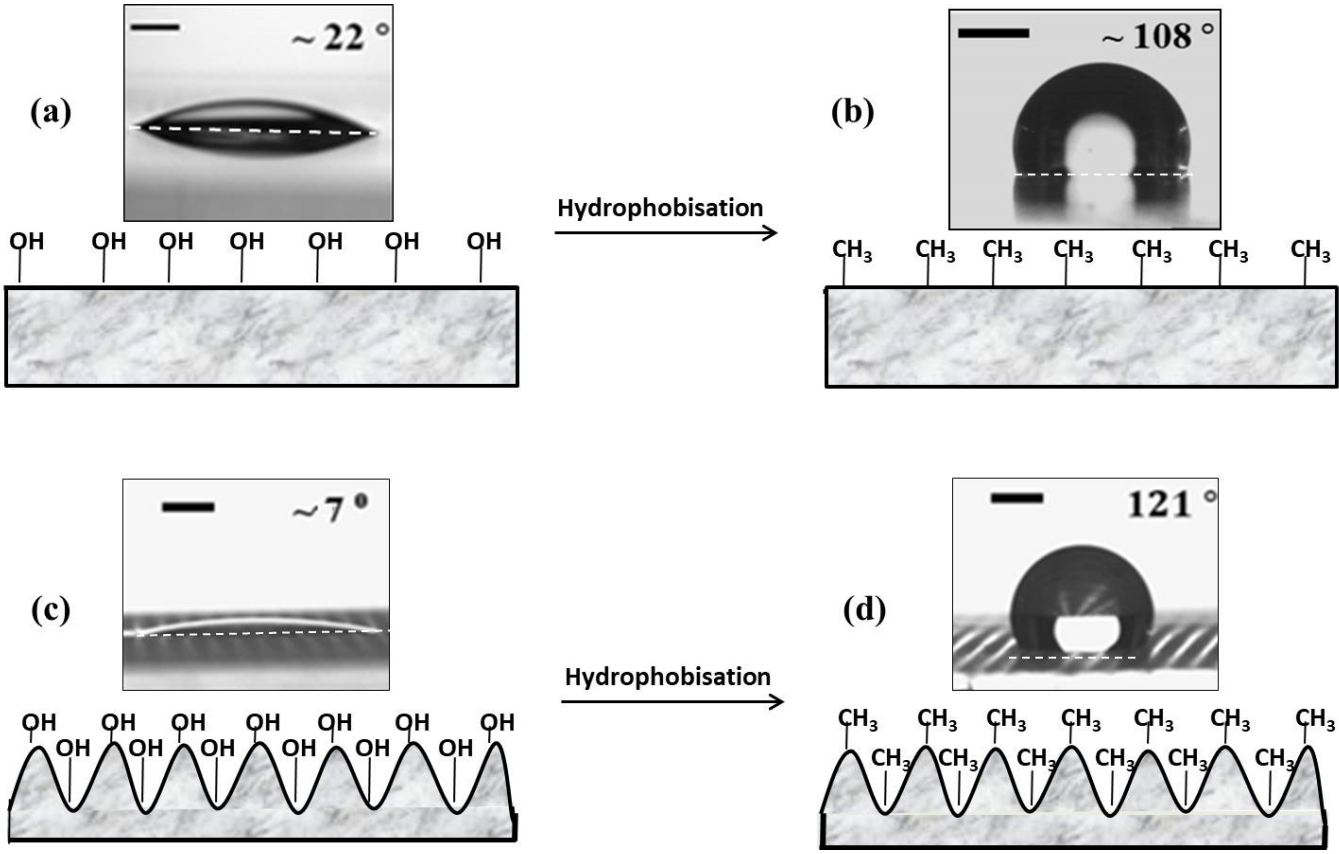

Figure 4. DSA images showing the configuration of water drops on smooth glass slides in air before hydrophobisation (a) and at maximum hydrophobisation (b); configuration of water drops on rough glass slides in air before hydrophobisation (c) and at maximum hydrophobisation (d). Under each image, the hypothetical distribution of reactive components of the respective surfaces is illustrated. Although the smooth and the rough glasses share the same body (projected) length, the actual length of the rough surface is larger because of its winding nature, thereby permitting more active sites species $\left(-\mathrm{OH}\right.$ or $\left.-\mathrm{CH}_{3}\right)$ on its surface. Consequently, rough surfaces become more concentrated with $-\mathrm{OH}$ (or $-\mathrm{CH}_{3}$ ) within the projected plane leading to amplified hydrophilicity (c) or hydrophobicity (d) compared to the smooth glass surfaces ( $\mathbf{a}$ or $\mathbf{b})$, respectively. All the scale bars represent $1 \mathrm{~mm}$. 
In Figure 4, unlike the smooth surface (Figure 4a), it seems plausible to infer that the roughness on the glass slides increased the surface area as well as the density of hydroxyl groups (bonding site) on the rough glass surface (Figure 4c). It is also reasonable to admit that the lower contact angle (or the amplified hydrophilicity) observed on the untreated rough glass (before exposure to DCDMS) was due to the higher density of the -OH on the rough surface, considering the affinity of water molecules to $-\mathrm{OH}$ groups [41-43] and not due to increased surface area only. Consequently, amplified hydrophobicity was observed during exposure of the rough glass slide to the DCDMS media because more $-\mathrm{CH}_{3}$ groups were grafted on the rough surfaces (Figure $4 \mathrm{~d}$ ) due to the higher concentration of active $-\mathrm{OH}$ groups on the rough glass surface. Therefore, a rough surface dominated with hydrophilic (or hydrophobic) active chemical species (bonds) may become more hydrophilic (or more hydrophobic) because the creation of roughness on its surface exposes more reactive sites.

Interestingly, the many active sites on the rough glasses in Figure $4 \mathrm{c}$, $\mathrm{d}$ tend to concentrate within a projected plane shared by the smooth surface of the same material. Thus, the projected plane of a rough surface impacts more or reacts faster than the smooth counterpart of the same length. This effect might become extremely pronounced on highly fractal surfaces. Following the above description, if roughness can regenerates additional reactive surfaces, it implies that the surface energy of rough materials will definitely change [20] since the surface energy depends on the functionality of the surface of the material [44-46]. However, the role of this extra surface energy has not been properly addressed in the model equations governing the wettability of rough surfaces; further investigations in this direction are needed.

\section{Conclusions}

Hydrophobisation reactions and wettability of smooth and rough glass surfaces have been studied. The aim of this study is not to challenge the existing wetting models at this stage but rather to reveal new ways of evaluating the wettability of rough surfaces through a facile experimental design. The result of the study shows that rough and smooth solid surfaces of the same material (glass) appear to be chemically different under the same conditions of hydrophobisation. Glass slides with rough surfaces exhibit higher rates of hydrophobisation than the corresponding slides with smooth surfaces. In addition, the result of the study highlights a deviation from the Wenzel mode of wetting by the rough glass surfaces, where a steady amplification of surface hydrophobicity was observed instead of hydrophilicity. It is also inferred that unlike the smooth glass surface, the roughened glass slide has the tendency to increase the surface density of - $\mathrm{OH}$ groups. Consequently, during exposure of the hydrophilic rough glass slide to the DCDMS media, more $-\mathrm{CH}_{3}$ groups are grafted onto the rough glass surfaces than on the smooth glass surfaces because of the higher concentration of the replaceable -OH groups on the rough glass surface. The Wenzel mode of wetting does not apply to the rough glass surfaces because its modification from the Young's equation is only based on physical dimension. This study will encourage further studies that will provide a greater understanding of quantitative and spatial distributions of functional or active species on rough solid surfaces and the effect of such components on surface energy and wettability.

Author Contributions: Conceptualization, E.E.U. Methodology, E.E.U., H.S.A.-S. and A.T.T.; Formal analysis, E.E.U., H.S.A.-S. and I.A.U.; Data curation, E.E.U. and I.A.U.; Writing-original draft preparation, E.E.U. and I.A.U.; Writing-review and editing, E.E.U., I.A.U., H.S.A.-S., A.T.T. and I.O.E. All authors have read and agreed to the published version of the manuscript.

Funding: This research received no external funding.

Conflicts of Interest: The authors declare no conflict of interest. 


\section{References}

1. Shin, S.; Seo, J.; Han, H.; Kang, S.; Kim, H.; Lee, T. Bio-Inspired Extreme Wetting Surfaces for Biomedical Applications. Materials 2016, 9, 116. [CrossRef]

2. Wen, L.; Tian, Y.; Jiang, L. Bioinspired Super-Wettability from Fundamental Research to Practical Applications. Angew. Chem. Int. Ed. 2015, 54, 3387-3399. [CrossRef]

3. Benedix, R.; Dehn, F.; Quaas, J.; Orgass, M. Application of titanium dioxide photocatalysis to create self-cleaning building materials. Lacer 2000, 5, 157-168.

4. Echeverría, J.C.; Faustini, M.; Garrido, J.J. Effects of the porous texture and surface chemistry of silica xerogels on the sensitivity of fiber-optic sensors toward VOCs. Sens. Actuators B Chem. 2016, 222, 1166-1174. [CrossRef]

5. Chen, X.M.; Weibel, J.A.; Garimella, S.V. Exploiting microscale roughness on hierarchical superhydrophobic copper surfaces for enhanced dropwise condensation. Adv. Mater. Interfaces 2015, 2, 1400480. [CrossRef]

6. Fan, X.; Niu, L.; Wu, Y.; Cheng, J.; Yang, Z. Assembly route toward raspberry-like composite particles and their controlled surface wettability through varied dual-size binary roughness. Appl. Surf. Sci. 2015, 332, 393-402. [CrossRef]

7. Chan, K.K.; Guarini, K.W.; Jones, E.C.; Saavedra, A.F.; Shi, L.; Singh, D.V. Low Temperature Fusion Bonding with High Surface Energy Using a Wet Chemical Treatment. U.S. Patent 2006O194414A1, 1 July 2004.

8. Decker, E.; Frank, B.; Suo, Y.; Garoff, S. Physics of contact angle measurement. Colloids Surf. A Physicochem. Eng. Asp. 1999, 156, 177-189. [CrossRef]

9. Stalder, I.; Bilgram, J.H. The measurement of the solid-liquid surface free energy of xenon. J. Chem. Phys. 2003, 118, 7981-7984. [CrossRef]

10. Gribanova, E.V.; Kuchek, A.E.; Larionov, M.I. Factors influencing the contact angle value. The contact angle, as a characteristic of the properties of solid surfaces. Russ. Chem. Bull. 2016, 65, 1-13. [CrossRef]

11. Ali, N.; Teixeira, J.A.; Addali, A.; Al-Zubi, F.; Shaban, E.; Behbehani, I. The effect of aluminium nanocoating and water pH value on the wettability behavior of an aluminium surface. Appl. Surf. Sci. 2018, 443, 24-30. [CrossRef]

12. Ali, N.; Teixeira, J.A.; Addali, A.; Saeed, M.; Al-Zubi, F.; Sedaghat, A.; Bahzad, H. Deposition of stainless steel thin films: An electron beam physical vapour deposition approach. Materials 2019, 12, 571. [CrossRef]

13. Young, T. III. An essay on the cohesion of fluids. Philos. Trans. R. Soc. Lond. 1805, 95, 65-87. [CrossRef]

14. Šiffalovič, P.; Jergel, M.; Benkovičová, M.; Vojtko, A.; Nádaždy, V.; Ivančo, J.; Bodík, M.; Demydenko, M.; Majková, E. Towards new multifunctional coatings for organic photovoltaics. Sol. Energy Mater. Sol. Cells 2014, 125, 127-132. [CrossRef]

15. Tyowua, A.T.; Targema, M.; Ubuo, E.E. Non-wettable surfaces-from natural to artificial and applications: A critical review. Rev. Adhes. Adhes. 2019, 7, 195-231. [CrossRef]

16. Wenzel, R.N. Resistance of solid surfaces to wetting by water. Ind. Eng. Chem. 1936, 28, 988-994. [CrossRef]

17. Cassie, A.B.D.; Baxter, S. Wettability of porous surfaces. Trans. Faraday Soc. 1944, 40, 546-551. [CrossRef]

18. Ning, T.; Xu, W.; Lu, S. Fabrication of superhydrophobic surfaces on zinc substrates and their application as effective corrosion barriers. Appl. Surf. Sci. 2011, 258, 1359-1365. [CrossRef]

19. Zeng, Q. Size matching effect on Wenzel wetting on fractal surfaces. Results Phys. 2018, 10, 588-593. [CrossRef]

20. Quéré, D. Wetting and roughness. Annu. Rev. Mater. Res. 2008, 38, 71-99. [CrossRef]

21. Wang, X.-S.; Yang, Z.-B.; Chen, J.; Fan, X.-B. Derivation of the Wenzel Equation for Contact Angles of Cylindrical Nano-Droplets on Rough Substrates. J. Comput. Theor. Nanosci. 2016, 13, 374-377. [CrossRef]

22. Shardt, N.; Elliott, J.A.W. Gibbsian thermodynamics of wenzel wetting (was wenzel wrong revisited). Langmuir 2020, 36, 435-446. [CrossRef]

23. Gao, L.; McCarthy, T.J. How wenzel and cassie were wrong. Langmuir 2007, 23, 3762-3765. [CrossRef]

24. McHale, G. Cassie and wenzel: Were they really so wrong? Langmuir 2007, 23, 8200-8205. [CrossRef]

25. Erbil, H.Y.; Cansoy, C.E. Range of applicability of the wenzel and cassie-baxter equations for superhydrophobic surfaces. Langmuir 2009, 25, 14135-14145. [CrossRef]

26. Malijevský, A. Does surface roughness amplify wetting? J. Chem. Phys. 2014, 141, 184703. [CrossRef]

27. Lin, Y.; Wang, L.; Krumpfer, J.W.; Watkins, J.; McCarthy, T.J. Hydrophobization of inorganic oxide surfaces using dimethylsilanediol. Langmuir 2013, 29, 1329-1332. [CrossRef] [PubMed]

28. Ulman, A. Formation and structure of self-assembled monolayers. Chem. Rev. 1996, 96, 1533-1554. [CrossRef]

29. Horozov, T.S.; Binks, B.P.; Aveyard, R.; Clint, J.H. Effect of particle hydrophobicity on the formatlon and collapse of fumed silica particle monolayers at the oil-water interface. Colloids Surf. A Physicochem. Eng. Asp. 2006, 282, 377-386. [CrossRef]

30. Nadiye-Tabbiruka, M.S. Interaction of Water with Silane Modified Aerosil Samples. Colloid Surf. Sci. 2017, 2, 118-124.

31. Grabowska, K.; Koniorczyk, M. Internal hydrophobization of cementitious materials by using of organosilicon compounds. In E3S Web of Conferences; EDP Sciences: Les Ulis, France, 2020; Volume 172, p. 14006.

32. Kang, T.; Jang, I.; Oh, S.-G. Surface modification of silica nanoparticles using phenyl trimethoxy silane and their dispersion stability in N-methyl-2-pyrrolidone. Colloids Surf. A Physicochem. Eng. Asp. 2016, 501, 24-31. [CrossRef]

33. Daniel, L.M.; Frost, R.L.; Zhu, H.Y. Edge-modification of laponite with dimethyl-octylmethoxysilane. J. Colloid Interface Sci. 2008, 321, 302-309. [CrossRef]

34. Horozov, T.; Aveyard, R.; Clint, A.J.H.; Binks, B.P. Order-Disorder Transition in Monolayers of Modified Monodisperse Silica Particles at the Octane-Water Interface. Langmuir 2003, 19, 2822-2829. [CrossRef] 
35. Liu, X.-Q.; Tang, R.-Z. Biological responses to nanomaterials: Understanding nano-bio effects on cell behaviors. Drug Deliv. 2017, 24, 1-15. [CrossRef]

36. Jia, J.; Xiong, T.; Zhao, L.; Wang, F.; Liu, H.; Hu, R.; Zhou, J.; Zhou, W.; Chen, S. Ultrathin N-doped Mo2C nanosheets with exposed active sites as efficient electrocatalyst for hydrogen evolution reactions. ACS Nano 2017, 11, 12509-12518. [CrossRef]

37. De Bartolo, L.; Catapano, G.; Della Volpe, C.; Drioli, E. The effect of surface roughness of microporous membranes on the kinetics of oxygen consumption and ammonia elimination by adherent hepatocytes. J. Biomater. Sci. Polym. Ed. 1999, 10, 641-655. [CrossRef] [PubMed]

38. Siau, S.; Vervaet, A.; Nalines, S.; Schacht, E.; Van Calster, A. Kinetic study of wet chemical treatments on the surface roughness of epoxy polymer layers for buildup layers: II. Oxidative Treatment of the surface. J. Electrochem. Soc. 2004, 151, C831. [CrossRef]

39. Choudhury, U.; Soler, L.; Gibbs, J.G.; Sanchez, S.; Fischer, P. Surface roughness-induced speed increase for active Janus micromotors. Chem. Commun. 2015, 51, 8660-8663. [CrossRef] [PubMed]

40. Li, M.; Zhao, Z.; Cheng, T.; Fortunelli, A.; Chen, C.-Y.; Yu, R.; Zhang, Q.; Gu, L.; Merinov, B.V.; Lin, Z.; et al. Ultrafine jagged platinum nanowires enable ultrahigh mass activity for the oxygen reduction reaction. Science 2016, 354, 1414-1419. [CrossRef] [PubMed]

41. Guan, K.; Lu, B.; Yin, Y. Enhanced effect and mechanism of SiO2 addition in super-hydrophilic property of TiO2 films. Surf. Coatings Technol. 2003, 173, 219-223. [CrossRef]

42. Jun, D.; Wu, Q.; Zhong, S.; Gu, X.; Liu, J.; Guo, H.; Zhang, W.; Peng, H.; Zou, J. Effect of hydroxyl groups on hydrophilic and photocatalytic activities of rare earth doped titanium dioxide thin films. J. Rare Earths 2015, 33, 148-153.

43. Yu, J.; Zhao, X.; Jimmy, C.Y.; Zhong, G.; Han, J.; Zhao, Q. The grain size and surface hydroxyl content of super-hydrophilic $\mathrm{TiO}_{2} / \mathrm{SiO}_{2}$ composite nanometer thin films. J. Mater. Sci. Lett. 2001, 20, 1745-1748. [CrossRef]

44. Al-Turaif, H. Relationship between surface chemistry and surface energy of different shape pigment blend coatings. J. Coat. Technol. Res. 2007, 5, 85-91. [CrossRef]

45. Baeta, N.; Maria, I.; Oliva, V.; Mrabet, B.; Connan, C.; Chehimi, M.M.; Delamar, M.; Hutton, S.; Roberts, A.; Benzarti, K. Surface chemistry of cement pastes: A study by X-ray photoelectron spectroscopy. Surf. Interface Anal. 2002, 33, 834-841.

46. Somorjai, G.A.; Li, Y. Impact of surface chemistry. Proc. Natl. Acad. Sci. USA 2011, 108, 917-924. [CrossRef] 